\title{
Chemical Reaction Engineering as a Bridge Between Nano and Macro World
}

\author{
Martino Di Serio* \\ Department of Chemical Sciences, Polytechnic and Basic Sciences School, University of Naples Federico II, Naples, Italy
}

Keywords: chemical reaction engineering, reactor, thermodynamics, kinetics, catalysis

\section{OPEN ACCESS}

Edited and reviewed by: Fengqi You, Cornell University, United States

*Correspondence: Martino Di Serio diserio@unina.it

Specialty section: This article was submitted to Chemical Reaction Engineering, a section of the journal Frontiers in Chemical Engineering

Received: 20 September 2019 Accepted: 15 October 2019

Published: 31 October 2019

Citation:

Di Serio M (2019) Chemical Reaction Engineering as a Bridge Between

Nano and Macro World.

Front. Chem. Eng. 1:2.

doi: 10.3389/fceng.2019.00002
Chemical Reaction Engineering started its history with the development of refinery and petrochemical industry at the beginning of the last century (Levenspiel, 1980). To come to commercial scale, laboratory data needs to be transferred toward industrial applications. That optimization of process performance demands for the merge of fundamentals sciences (chemistry, physics, mathematics-reactor modeling) in a new applied discipline: Chemical Reaction Engineering (CRE) (Levenspiel, 1998; Froment et al., 2010; Scott Fogler, 2016). In the recent decades, an increasing trend is observed in the use of biology and particularly biocatalysis for application in biotechnology (Bischoff, 1966; Katoh et al., 2015).

The main fields of chemistry belonging to CRE are thermodynamics, kinetics and catalysis (Levenspiel, 1998; Froment et al., 2010; Scott Fogler, 2016). The classical kinetic approach provides the development of know-how about the conduction of a kinetic test, drawing the lines about the correct definition of the minimum number of experiments needed to understand the kinetics of a reaction network (Salmi et al., 2010; Santacesaria and Tesser, 2018). The main concern of this approach is the need to determine kinetic parameters from the collected data, most likely defining a reaction mechanism. The experimental data implementation is becoming nowadays more and more sophisticated, moving to a deeper understanding of the micro-scale of a reaction. To describe the observed chemical phenomena, the underlying physical phenomena need also to be considered (Ramachandran and Chaudhari, 1983; Dudukovic et al., 1999).

Currently, the boundary in CRE is pushed from the macro-meso-micro- to the nano-electronic scale (Lerou and Ng, 1996; Šivec et al., 2019). This is enabled by advances made in the development of experimental equipment for investigation. For instance, nowadays it is possible to follow the kinetics of a reaction with in-situ operando techniques allowing the determination of realistic reaction mechanism (Gracia et al., 2003; Frenken and Groot, 2017; Li et al., 2019). To describe the phenomena at the nano scale it is necessary to use a quantum mechanics approach. Increasingly, DFT is coupled with kinetic modeling, coined microkinetic, demonstrating high predictability of the reaction kinetics (Alexopoulos et al., 2016; Hussain Motagamwala et al., 2019). In the future, efforts in this field are expected to provide important insights into molecular phenomena and to foster process improvement.

A great disruptive transformation of reactor design has made its way from academia to industrial use. New concepts are now available, such as:

- the intensification of the processes with multifunctional reactors (Cho et al., 1980; Taylor and Krishna, 2000; Rodrigues et al., 2012; Gallucci et al., 2013; Russo et al., 2018)

- the opening the novel process windows by microreactors (Kiwi-Minsker and Renken, 2005; Hessel, 2009);

- the use of alterative way to transfer energy to the reactive system (mainly with microwaves or cavitational reactors; Nüchter et al., 2004; Gogate, 2008). 
All the above new concepts have the same objective: on the one hand to optimize the processes by reducing the required energy and waste and, on the other hand, to increase the safety. Yet, although they can offer more novel process windows, with only a part of that having been released,- the new types of reactors slowly change the way of carrying processes.

Also concerning macro-scale processing substantial efforts have been made to improve technical instrumentations, allowing the precise determination of the physical properties of fluids and solids inside the reactors (e.g. tomography, high resolution IR camera, MRI imaging) (Kumar et al., 1997; Gladden et al., 2003; Rafique et al., 2004).Therefore, the classical approach of describing physical phenomena in simple terms is moving in a more sophisticated and realistic direction: from the use of dimensionless numbers to computational fluid-dynamics. Classically, for example, when simulating continuous reactors, the momentum balance equations are neglected, and the fluiddynamics is described in terms of pressure-drop correlations. This approach is usually valid, but what if the geometry of the packing is non-conventional? What if the fluid-dynamics is far from being classical? It has been demonstrated that CFD modeling can be coupled with a classical kinetic approach to consider irregular geometries of non-conventional packing materials, such as foams (Della Torre et al., 2016).

These approaches are at the forefront of CRE: scientists specialized in physical chemistry and fluid-dynamics develop tools for the deep investigation of the fundamentals of the cited disciplines. It is evident that classical CRE is the joining link between the two approaches.

\section{REFERENCES}

Alexopoulos, K., John, M., Van der Borght, K., Galvita, V., Reyniers, M.-F., and Marin, G. B. (2016). DFT-based microkinetic modeling of ethanol dehydration in H-ZSM-5. J. Catal. 339, 173-185. doi: 10.1016/j.jcat.2016.04.020

Anastas, P. T., and Zimmerman, J. B. P. (2003). Design through the 12 principles of green engineering. Environ. Sci. Technol. 37, 94-101A. doi: 10.1021/es032373g

Bischoff, K. B. (1966). Optimal continuous fermentation reactor design. Can. J. Chem. Eng. 44, 281-284. doi: 10.1002/cjce.5450440507

Cho, B. K., Carr, R. W., and Aris, R. (1980). A continuous chromatographic reactor. Chem. Eng. Sci. 35, 74-81. doi: 10.1016/0009-2509(80)80072-8

Constable, D. J. C., Gonzalez, M., and Morton, S. A. (2016). "Towards more sustainable chemical engineering processes: integrating sustainable and green chemistry into the engineering design process," Sustainability in the Design, Synthesis and Analysis of Chemical Engineering Processes, eds G. RuizMercado and H. Cabezas (Oxford, UK: Butterworth-Heinemann), 1-34. doi: 10.1016/B978-0-12-802032-6.00001-3

Della Torre, A., Lucci, F., Montenegro, G., Onorati, A., Dimopoulos Eggenschwiler, P., Tronconi, E., et al. (2016). CFD modelling of catalytic reactions in open-cell foam substrates. Comput. Chem. Eng. 92, 55-63. doi: 10.1016/j.compchemeng.2016.04.031

Dudukovic, M. P., Larachi, F., and Mills, P. L. (1999). Multiphase reactors revisited. Chem. Eng. Sci. 54, 1975-1995. doi: 10.1016/S0009-2509(98)00367-4

Frenken, J., and Groot, I. (2017). Operando Research in Heterogeneous Catalysis. Cham: Springer. doi: 10.1007/978-3-319-44439-0

Froment, G. F., Bischoff, K. B., and De Wilde, J. (2010). Chemical Reactor Analysis and Design, 3rd Edn. New York, NY: John Wiley and Sons.

Gallucci, F., Fernandez, E., Corengia, P., and van Sint Annaland, M. (2013). Recent advances on membranes and membrane reactors for hydrogen production. Chem. Eng. Sci. 92, 40-66. doi: 10.1016/j.ces.2013.01.008
In the development of CRE the evolution of computational tools (both hardware and software) is gaining a fundamental role. Computational times are becoming ever shorter, high performance calculators are released virtually every day, supporting the development of reliable and more sophisticated kinetic and reactor models. Great efforts have been made in the past to develop adequate mathematical models. The research in the field is still taking on new challenges for chemical reaction engineering (Varma and Morbidelli, 1997; Rasmuson et al., 2014).

What is the Grand Challenge of CRE? The main challenge is to build a reliable bridge from the nano to the macro scale, that allows to predict the behavior of a whole chemical process, starting from its definition by scratch. To do this it is certainly necessary to continue researching the boundaries (the nano dimensions and the detailed description of fluid dynamics phenomena) without compromising the use of classical approaches. It must be remembered that often the simplest approaches lead to the faster and to the most reliable results (KISS principle-keep it simple, stupid). Both fundamental and applied research are equally important to achieve the final objective: to develop new chemical processes for the sake of increasing safety and decreasing depletion of natural resources and the total environmental impact, following the 12 principles of green engineering (Anastas and Zimmerman, 2003) and sustainable process design (Constable et al., 2016).

\section{AUTHOR CONTRIBUTIONS}

\author{
MD devised the manuscript concept and writing.
}

Gladden, L. F., Lim, M. H. M., Mantle, M. D., Sederman, A. J., and Stitt, E. H. (2003). MRI visualisation of two-phase flow in structured supports and trickle-bed reactors. Catal. Today 79-80, 203-210. doi: 10.1016/S0920-5861(03)00006-3

Gogate, P. R. (2008). Cavitational reactors for process intensification of chemical processing applications: a critical review. Chem. Eng. Process. 47, 515-527. doi: 10.1016/j.cep.2007.09.014

Gracia, F. J., Bollmann, L., Wolf, E. E., Miller, J. T., and Kropf, A. J. (2003). In situ FTIR, EXAFS, and activity studies of the effect of crystallite size on silica-supported Pt oxidation catalysts. J. Catal. 220, 382-391. doi: 10.1016/S0021-9517(03)00296-3

Hessel, V. (2009). Novel process windows - gate to maximizing process intensification via flow chemistry. Chem. Eng. Technol. 32, 1655-1681. doi: $10.1002 /$ ceat.200900474

Hussain Motagamwala, A., Ball, M. R., and Dumesic, J. A. (2019). Microkinetic analysis and scaling relations for catalyst design. Ann. Rev. Chem. Biomol. Eng. 9, 413-450. doi: 10.1146/annurev-chembioeng-060817-084103

Katoh, S., Horiuchi, J., and Yoshida, F. (2015). Biochemical Engineering: A Textbook for Engineers, Chemists and Biologists, 2nd Edn. Weineim: WileyVCH. doi: 10.1002/9783527684984

Kiwi-Minsker, L., and Renken, A. (2005). Microstructured reactors for catalytic reactions. Catal. Today 110, 2-14. doi: 10.1016/j.cattod.2005.09.011

Kumar, S. B., Moslemian, D., and Duduković, M. P. (1997). Gas-holdup measurements in bubble columns using computed tomography. AIChE J. 43, 1414-1425. doi: 10.1002/aic.690430605

Lerou, J. J., and Ng, K. M. (1996). Chemical Reaction Engineering a multiscale approach to a multiobjective task. Chem. Eng. Sci. 51, 1595-1614. doi: 10.1016/0009-2509(96)00022-X

Levenspiel, O. (1980). The coming-of-age of chemical reaction engineering. Chem. Eng. Sci. 35, 1821-1839. doi: 10.1016/0009-2509(80)80132-1 
Levenspiel, O. (1998). Chemical Reaction Engineering, 3rd Edn. New York, NY: John Wiley and Sons.

Li, X., Yang, X., Zhang, J., Huang, Y., and Liu,. B. (2019). In situ/operando techniques for characterization of single-atom catalysts. ACS Catal. 9, 2521-2531. doi: 10.1021/acscatal.8b04937

Nüchter, M., Ondruschka, B., Bonrath, W., and Gum, A. (2004). Microwave assisted synthesis - a critical technology overview. Green Chem. 6, 128-141. doi: 10.1039/B310502D

Rafique, M., Chen, P., and Duduković, M. P. (2004). Computational modeling of gas-liquid flow in bubble columns. Rev. Chem. Eng. 20, 225-375. doi: 10.1515/REVCE.2004.20.3-4.225

Ramachandran, P. A., and Chaudhari, R. V. (1983). Three Phase Catalytic Reactors, London: Gordon and Breach Science Publishers.

Rasmuson, A., Andersson, B., Olsson, L., and Andersson, R. (2014). Mathematical Modeling in Chemical Engineering. Cambridge: Cambridge University Press. doi: 10.1017/CBO9781107279124

Rodrigues, A. E., Pereira, C. S. M., and Santos,. J. C. (2012). Chromatographic reactors. Chem. Eng. Technol. 35, 1171-1183. doi: 10.1002/ceat.201100696

Russo, V., Tesser, R., Rossano, C., Vitiello, R., Turco, R., Salmi, T., et al. (2018). Chromatographic reactor modelling. Chem. Eng. J. 377, 119692. doi: $10.1016 /$ j.cej.2018.08.078

Salmi, T. O., Mikkola, J. P., and Warna, J. P. (2010). Chemical Reaction Engineering and Reactor Technology. Boca Raton, FL: CRC Press. doi: $10.1201 / 9781439894859$
Santacesaria, E., and Tesser, R. (2018). The Chemical Reactor from Laboratory to Industrial Plant. Cham: Springer International Publishing AG. doi: 10.1007/978-3-319-97439-2

Scott Fogler, H. (2016). Elements of Chemical Reaction Engineering, 5th Edn. Boston, MA: Prentice Hall.

Šivec, R., Grilc, M., Huš, M., and Likozar, B. (2019). Multiscale modeling of (hemi)cellulose hydrolysis and cascade hydrotreatment of 5hydroxymethylfurfural, furfural, and levulinic acid. Ind. Eng. Chem. Res. 58, 16018-16032. doi: 10.1021/acs.iecr.9b00898

Taylor, R., and Krishna, R. (2000). Modelling reactive distillation. Chem. Eng. Sci. 55, 5183-5229. doi: 10.1016/S0009-2509(00)00120-2

Varma, A., and Morbidelli, M. (1997). Mathematical Methods in Chemical Engineering. Oxford: Oxford University Press.

Conflict of Interest: The author declares that the research was conducted in the absence of any commercial or financial relationships that could be construed as a potential conflict of interest.

Copyright (c) 2019 Di Serio. This is an open-access article distributed under the terms of the Creative Commons Attribution License (CC BY). The use, distribution or reproduction in other forums is permitted, provided the original author(s) and the copyright owner(s) are credited and that the original publication in this journal is cited, in accordance with accepted academic practice. No use, distribution or reproduction is permitted which does not comply with these terms. 